\title{
Effect of Bcl-2 overexpression on cell cycle and antibody productivity in chemostat cultures of myeloma NSO cells
}

\begin{abstract}
Chemostat cultures of NS0 cell lines were carried out at dilution rates ranging from $0.8 \mathrm{~d}-1$ to 0.2 d-1. Compared with the control, the viable cell density of the Bcl-2 cell line was approximately $10 \%$ higher at $0.8 \mathrm{~d}-1$ and increased to $55 \%$ when the dilution rate was reduced to $0.2 \mathrm{~d}-1$. As the dilution rate was reduced, the viability of the two cultures diverged reaching a difference of $43 \%$ at $0.2 \mathrm{~d}-1$. The specific growth rate of the control cells was the same as the dilution rate down to a value of $0.6 \mathrm{~d}-1$. By contrast, the specific growth rate of Bcl-2 cells was parallel to the dilution rate down to a value as low as $0.3 \mathrm{~d}-1$. For both NS0 cell lines, the G1 cell population decreased, while the $\mathrm{S}$ and G2/M cell populations increased as the dilution rate was reduced. The antibody titer of the control cells increased from 7 to 21 $\mu \mathrm{g} \cdot \mathrm{ml}-1$ as the dilution rate was reduced from 0.8 to $0.2 \mathrm{~d}-1$. With an initial increase from 2 to $15 \mu \mathrm{g} \cdot \mathrm{ml}-1$ as the dilution rate was reduced from 0.8 to $0.4 \mathrm{~d}-1$, the antibody titer of the Bcl-2 cells remained constant as the dilution rate was further reduced to $0.2 \mathrm{~d}-1$. A good correlation between specific antibody production rate and the percentage of G2/M cells was observed. (c) 2005, The Society for Biotechnology.
\end{abstract}

Keyword: Apoptosis; bcl-2; Bioreactor; Chemostat culture; NS0 myeloma cells 